\title{
A PESQUISA DE MERCADO NAS MICROEMPRESAS DO SETOR DE VIANDAS E MARMITARIAS DE SANTA MARIA-RS
}

\author{
André Soares Veiga ${ }^{1}$ \\ Ezequiel Redin ${ }^{2}$
}

Resumo: As microempresas do ramo de viandas e marmitarias desempenham uma atividade importante nos centros urbanos, pois o ramo da alimentação é indispensável no meio familiar. O objetivo desta investigação é analisar a utilização da pesquisa de mercado pelos empreendedores do ramo de fornecimento de viandas e marmitarias localizados no centro do município de Santa Maria, Rio Grande do Sul. Os empresários tiveram trajetórias distintas para a criação das empresas, cinco deles já tinham experiências na área de alimentação. Os entrevistados entendem que a pesquisa de mercado serve para analisar o segmento que o empreendedor quer investir, verificar a existência de público suficiente para o empreendimento, em qual região atuará e quais as necessidades dos clientes. Quanto à metodologia, este estudo caracteriza-se como pesquisa descritiva e qualitativa. Os dados coletados deram-se por meio de entrevistas com roteiro semiestruturado, as quais foram aplicadas em dez microempresas, situadas na região central da cidade de Santa Maria, no ano de 2016. Os resultados demostraram que os empresários conhecem ou já ouviram falar e sabem a real importância que a ferramenta de pesquisa de mercado traz em benefício dos negócios, mas não a utilizam adequadamente, pois realizam apenas pesquisas de menor expressão e que não são suficientes para minimizar os riscos que o mercado alimentício apresenta. É necessária uma atenção maior dos empreendedores quanto à ferramenta de pesquisa de mercado, pois, usando-a de maneira técnica, ela pode tornar-se um instrumento importante para a procura de informações pertinentes ao empreendimento e à obtenção de dados úteis para a formação de uma empresa.

Palavras-chave: Pesquisa de mercado; Microempresa; Consumo alimentício; Processo de decisão.

\section{Market research in micro-enterprises in the food and beverage sector of Santa Maria-RS}

\footnotetext{
${ }^{1}$ Bacharel em Administração pela Faculdade Metodista de Santa Maria, Santa Maria, Rio Grande do Sul.

${ }^{2}$ Tecnólogo em Agropecuária: Sistemas de Produção (UERGS) CREA RS 160488; Bacharel em Administração (ULBRA); Licenciatura plena para a Educação Profissional (UFSM); Especialista em Gestão Pública Municipal (UFSM); Especialista em Tecnologias de Informação e Comunicação aplicadas à Educação (UFSM); Mestre e Doutor em Extensão Rural (PPGExR/UFSM); Editor da Revista Extensão Rural; Membro da Academia Centro Serra de Letras; Tesoureiro da Associação Riograndense dos Tecnólogos (ARTECNOL). Professor da Faculdade Metodista de Santa Maria (FAMES).
} 


\begin{abstract}
The micro-enterprises in the branch of pastry and marinade play an important role in the urban centers, since the food sector is indispensable in the family environment. The objective of this research is to analyze the use of market research by the entrepreneurs in the food supply chain, located in the center of the municipality of Santa Maria, Rio Grande do Sul. Entrepreneurs had different paths for the creation of companies, five of them already Had experiences in the area of food. The interviewees understand that the market research serves to analyze the segment that the entrepreneur wants to invest, to verify the existence of sufficient public for the enterprise, in which region will act and what the clients needs. As for the methodology, this study is characterized as descriptive and qualitative research. The data were collected through semi-structured interviews, which were applied in ten micro-enterprises, located in the central region of Santa Maria, in the year 2016. The results showed that entrepreneurs know or have already heard about and know The real importance that the market research tool brings to the benefit of the business, but do not use it properly, because they only carry out researches of lesser expression and that are not enough to minimize the risks presented by the food market. More attention is needed from the entrepreneurs regarding the market research tool, since, using it in a technical way, it can become an important instrument for the search of information pertinent to the enterprise and for obtaining useful data for the formation of a company.
\end{abstract}

Keywords: Market research; Micro enterprise; Food consumption; Decision-making process.

Resumen: Las microempresas de la rama de viandas y marmitarias desempeñan una actividad importante en los centros urbanos, pues la rama de la alimentación es indispensable en el medio familiar. El objetivo de esta investigación es analizar la utilización de la investigación de mercado por los emprendedores del ramo de suministro de viandas y marmitas ubicados en el centro del municipio de Santa Maria, Rio Grande do Sul. Los empresarios tuvieron trayectorias distintas para la creación de las empresas, cinco de ellas ya Tenían experiencias en el área de alimentación. Los encuestados entienden que la investigación de mercado sirve para analizar el segmento que el emprendedor quiere invertir, verificar la existencia de público suficiente para el emprendimiento, en qué región actuará y cuáles las necesidades de los clientes. En cuanto a la metodología, este estudio se caracteriza como una investigación descriptiva y cualitativa. Los datos recogidos se dieron a través de entrevistas con itinerario semiestructurado, las cuales se aplicaron en diez microempresas, situadas en la región central de la ciudad de Santa María, en el año 2016. Los resultados demostraron que los empresarios conocen o ya han oído hablar y saben La real importancia que la herramienta de investigación de mercado trae en beneficio de los negocios, pero no la utilizan adecuadamente, pues realizan apenas investigaciones de menor expresión y que no son suficientes para minimizar los riesgos que el mercado alimenticio presenta. Es necesaria una atención mayor de los emprendedores en cuanto a la herramienta de investigación de mercado, pues, usándola de manera técnica, puede convertirse en un instrumento importante para la búsqueda de informaciones pertinentes al emprendimiento y la obtención de datos útiles para la formación de una empresa. 
Palabras clave: Investigación de mercado; Microempresa; Consumo alimenticio; Procedimiento de decisión.

\section{INTRODUÇÃO}

A ferramenta de pesquisa de mercado corresponde à procura de informações e à obtenção de dados úteis para a formação de uma empresa, assim como para a revalidação ou o redirecionamento das estratégias do negócio. Ela proporciona o conhecimento prévio da reação dos consumidores habituais ou futuros clientes diante de novos produtos ou novas oportunidades e as suas características ou até mesmo para conhecer-se e avaliar a pertinência de lançamentos efetuados pelos concorrentes da empresa. Para Maximiano (2011), empresa é uma atividade que tem como finalidade oferecer produtos e serviços para atender as necessidades dos clientes e, com isso, obter lucro.

De acordo com o Serviço Brasileiro de Apoio às Micro e Pequenas Empresas (SEBRAE, 2015), o Brasil é considerado como um dos países mais empreendedores do mundo. O empreendedorismo é um fenômeno local, sendo que três em cada dez brasileiros adultos, entre 18 e 64 anos, possuem uma empresa ou estão envolvidos com a criação de um negócio próprio. Dessa forma, diversas instituições públicas e privadas têm investido em pesquisa e incentivo a novos empreendimentos (SEBRAE, 2015).

As microempresas (ME) são importantes para a geração de emprego e renda no Brasil, contribuindo para a oferta de produtos e serviços para toda a sociedade. Esse tipo de empreendimento representa $99 \%$ das empresas do setor de serviços e $99,1 \%$ das empresas do setor de comércio, sendo elas que geram $80,2 \%$ dos empregos do comércio, $60 \%$ do emprego formal do país, contribuem com $20 \%$ do Produto Interno Bruto (PIB) brasileiro e constituem relevante instrumento de inclusão econômica e social (SEBRAE, 2015).

De acordo com o portal Empresômetro das Micros e Pequenas Empresas, dados de 2016 apontam 28.830 empresas ativas em Santa Maria/RS, o que representa 0,2\% do total de empresas do Brasil, sendo que as Micro e Pequenas Empresas (MPEs) são 26.615 (92,3\% do total de empresas ativas em Santa Maria/RS). O índice de mortalidade (fechamento de empresas) é 293 empresas neste município ou 0,2\% do total de MPEs fechadas no Brasil no ano de 2016. 
Esses índices de fechamento mostram o quão desafiador é abrir e manter uma empresa, o que requer vários pré-requisitos, tais como capital inicial, disposição, dedicação e outros. Além disso, um fator essencial é o conhecimento do mercado de atuação e dos desejos de seus clientes, porque, através desse conhecimento, o empreendedor pode minimizar as chances de erro na abertura e na condução de seus negócios. O baixo conhecimento do mercado de atuação pode ser apontado como uma razão determinante para o fechamento precoce dos empreendimentos, à medida que muitos empresários conhecem pouco o mercado que atuam.

Neste sentido, conhecer e utilizar as pesquisas de mercado torna-se fundamental para ampliar as informações e diminuir os riscos do negócio. Malhotra (2011, p. 45) define que pesquisa de mercado é “a identificação, coleta, análise e disseminação de informações de forma sistemática e objetiva e seu uso para assessorar a gerência na tomada de decisões relacionadas à identificação e solução de problemas (e oportunidades) de marketing”.

Em razão das fortes oscilações na economia nos últimos anos, as microempresas de alimentação influenciaram no modo de vida e consumo da população. Com isso, tem-se observado um aumento expressivo de pessoas que fazem alimentação fora da residência. Tal fato acontece pela dificuldade com os longos deslocamentos, a intensa jornada de trabalho, estudos, entre outras atividades que determinam que a comida seja terceirizada. Dessa maneira, a alimentação realizada fora de casa ou a compra dela em empresas de alimentação para almoço na residência deixaram de ser uma estratégia de lazer e passaram a constituir-se em uma questão de necessidade para alguns e, para outros, uma comodidade. Neste sentido, houve a expansão e o crescimento de redes de restaurantes, especialmente, aqueles que distribuem viandas e marmitex. Esse tipo de serviço traz benefícios para o cliente, pois proporciona grande diversidade de alimentos, agilidade no atendimento e, algumas vezes, custos mais acessíveis.

Nesse contexto, a crescente demanda do consumidor pela aquisição da comida e o aumento de empresas de viandas e marmitex demonstram um movimento empreendedor que se readapta para atender as necessidades locais da cidade de Santa Maria, RS. Desse modo, esta pesquisa procura compreender com que frequência os empresários do ramo de fornecimento de viandas e marmitarias do bairro central da cidade de Santa Maria recorrem à ferramenta de pesquisa de mercado para embasar as suas tomadas de decisões gerenciais? 
O objetivo geral desta investigação é analisar a utilização da pesquisa de mercado pelos empreendedores do ramo de fornecimento de viandas e marmitarias localizados no centro do município de Santa Maria, Rio Grande do Sul. Ademais, como objetivos específicos, pretende-se: a) descrever o processo de criação das empresas do setor de alimentos em Santa Maria, RS; b) identificar, entre as empresas, aquelas que utilizam a pesquisa de mercado como ferramenta gerencial; c) verificar se os gestores das organizações obtiveram auxílio e acesso facilitado às informações necessárias para a criação e a manutenção de seus empreendimentos; e d) analisar o conhecimento prévio do mercado pelos gestores antes de estabelecerem-se no ramo de viandas e marmitarias na região central da cidade de Santa Maria, RS.

Justifica-se a necessidade deste estudo, pois a literatura de gestão aponta o profundo conhecimento do mercado de atuação como sendo um aspecto fundamental tanto para a abertura de uma empresa como para a contínua validação do direcionamento da estratégia de mercado, no entanto, ainda poucos estudos sobre o ramo de viandas e marmitarias foram realizados. Neste sentido, a pesquisa de mercado viabiliza o estudo das condições econômicas do negócio, ou seja, é um instrumento que ajuda a compreender o conjunto formado pela relação entre concorrente, fornecedor e consumidor, que pode atender às necessidades e aos desejos dos clientes.

Além disso, ressalta-se que o ramo de viandas e marmitarias tem representado um importante modelo de negócio, devido às condições da rotina de vida atual. $\mathrm{O}$ presente estudo mostra-se inovador, uma vez que a literatura científica ainda é carente de pesquisas sobre esse tipo de microempresa que envolve um saber artesanal (ato de cozinhar), com um saber gerencial (ato de administrar). Do mesmo modo, esta pesquisa pode contribuir no âmbito acadêmico para auxiliar os estudantes que buscam ampliar os seus conhecimentos diante do assunto, em especial, quanto à aplicação em microempresas.

Dessa forma, o presente artigo está estruturado em cinco seções: a introdução, contendo o problema de pesquisa, o objetivo geral e os objetivos específicos, além da justificativa. A segunda seção apresenta a revisão de literatura com as principais definições teóricas sobre o contexto das microempresas, a questão da alimentação, de consumo e as organizações e o processo de tomada de decisão. Na terceira seção, descreve-se a metodologia utilizada na aplicação da pesquisa com foco na investigação bibliográfica e descritiva com abordagem qualitativa, assim como o uso do roteiro 
semiestruturado aplicado em dez microempresas na região central da cidade de Santa Maria/RS. Na sequência, aborda-se a apresentação e as discussões de resultados através de entrevistas realizadas em empresas do setor de viandas e marmitarias. Por último, são citadas as considerações finais desta pesquisa.

\section{REVISÃO DE LITERATURA}

No mundo do empreendedorismo, em especial, de negócios inovadores ainda há certa ambiguidade na literatura. De acordo com Filion (1999, p. 6), “os economistas associam o empreendedor com inovação, enquanto os comportamentalistas se concentram nos aspectos criativos e intuitivo". O autor trata de definir os empreendedores com base na inovação e percebe-os como os originadores da mudança. Em suas palavras: "Empreendedor é uma pessoa criativa marcada pela capacidade de estabelecer e atingir objetivos e que mantém alto nível de consciência do ambiente em que vive, usando-a para detectar oportunidades de negócios” (FILION, 1999, p. 19).

É graças ao chamado espírito empreendedor que o Brasil conta com grande número de microempresas, além de o país ser o mais empreendedor. Na sequência, são apresentados conceitos específicos desse formato de negócio. Nesta seção, são elencados conceitos relevantes baseados na literatura de microempresas, consumo de alimentos, pesquisas de mercado e processo de decisão.

\subsection{MICROEMPRESA}

As microempresas desempenham um papel importante na economia brasileira, representando uma parcela considerável no mercado, porém, têm estado diante de inúmeros desafios devido a tantas dificuldades econômicas e administrativas.

Conforme o Estatuto Nacional dos Estados e Municípios, na legislação nacional, as Micro e Pequenas Empresas (MPE) são definidas conforme o faturamento (artigo $3^{\circ}$ da LC $\mathrm{n}^{\circ}$ 123). Microempresa é toda a sociedade empresária, sociedade simples, empresa individual de responsabilidade limitada e o empresário individual que aufira, em cada ano-calendário, receita bruta igual ou inferior a $\mathrm{R} \$ 360.000 .00$ (trezentos e sessenta mil reais). (SEBRAE, 2016). 
O conceito de microempresa é importante para o estudo porque as dez empresas estudadas enquadram-se nesse formato. "As pequenas empresas estão atualmente numa luta para sobrevirem e se manterem competitivas frente às mudanças sociais, políticas e econômicas que caracterizam a globalização cada vez mais acentuada”. (PELISSARI, 2007, p. 150).

Takahashi (2005 apud RAMOS; CARVALHO; CUNHA, 2006, p. 258), em relação à microempresa, afirma que "As MPEs, oferecem a absoluta maior parte dos empregos no país. De sua modernização e expansão dependem a curto prazo o surgimento de mais trabalho e emprego para a população". Uma microempresa é considerada de pequeno porte e conta com, no máximo, dez empregados, sendo que o proprietário costuma contribuir com o seu próprio trabalho. O seu faturamento é reduzido, permitindo que o pagamento de seus tributos seja simplificado.

Já Deakins (1996 apud HOFFMANN; HOFFMANN; CANCELLIER, 2009)pondera que as pequenas empresas são de suma importância para o crescimento e a maturidade da economia, assim como, no processo de evolução, é relevante a contribuição que apresentam ao gerar oportunidades para o aproveitamento de uma grande fração de força de trabalho e ao fomento e desenvolvimento empresarial.

Segundo o Sebrae (2015), as ME no Brasil nunca foram tantas e nunca tiveram tanta importância econômica. O Brasil já tem aproximadamente seis milhões de micro e pequenas empresas (colocando o país no topo dos países mais empreendedores do mundo), sendo que esse total de empresas corresponde a $97 \%$ de todas as empresas do país, ficando apenas 3\% do total com as empresas médias e grandes.

Maculan (1995), ao tratar da significância das ME, lembra que não obstante as micro, pequenas e médias empresas estarem inseridas numa série de problemas que se lhes apresenta dentro de um cenário preocupante por possuírem bases financeiras limitadas, por atuarem em setores relativamente tradicionais, pela restrita disponibilidade de recursos humanos qualificados, pela pouca sofisticada estrutura organizacional e pela falta de competência de planejamento, não se pode deixar de reconhecer a sua importância ao longo dos últimos anos. Adiante, aborda-se sobre alimentação, consumo e organizações.

\subsection{ALIMENTAÇÃO, CONSUMO E ORGANIZAÇÕES}


A alimentação da população em geral é muito diversificada quando se trata de comer fora do ambiente familiar, pois carece de tempo e criatividade para fazer em casa algo saudável. Por isso, durante o dia, as famílias recorrem a restaurantes que servem refeições a peso (por quilo), que são relativamente econômicos, pois só se paga o que se serve. Santos et al. (2011, p. 316 apud RAYMUNDO, 2015) afirmam que "o restaurante por peso é uma modalidade de serviço muito utilizada na realidade brasileira e representa uma alternativa saudável de alimentação fora de casa". Por outro lado, se as famílias não quiserem sair de casa, elas podem apanhar viandas para suprir as suas necessidades. Em Santa Maria, cidade universitária e baseada em bens e serviços, as viandas são estratégias alimentares solicitadas pela sociedade que tem como foco a qualificação ou o trabalho intensivo.

Já durante a noite, a dieta alimentar tem relação com a aquisição de lanches. Conforme Bleil (1998, p. 2), “o sanduíche e os refrigerantes ganham preferência quando o mais importante é a praticidade e a rapidez". Segundo relatos de Wikner et al, (2007); Graman (2010, p. 357 apud ALCÂNTARA; FERREIRA 2013), “um dos desafios das atuais cadeias de suprimento consiste em produzir exatamente o que os consumidores desejam, no local apropriado, com custo e tempo desejados pelo consumidor".

Neste sentido, emerge a facilidade e a comodidade de ganhar espaço no mercado de alimentos. Bleil (1998, p. 9) esclarece que "a vida nas cidades grandes minimizou a importância do ato alimentar. Parece não se importar muito o que se come, com que se come e como se come". Essa reflexão do autor pode ser relacionada com o trabalhador ou o próprio estudante que se alimenta no intervalo do almoço com lanches e refrigerantes em detrimento de refeições mais saudáveis.

Barbosa (2009) assinala que "tudo isso nos leva à constatação de que nos dias atuais o comer de uma atividade corriqueira, prazerosa, privada e familiar transformouse em uma atividade altamente consciente, regulada e política”.

Há vários tipos de empreendimentos na área de alimentação, dentre eles, encontra-se o famoso a la carte. Zanella (2007, p. 316 apud Raymundo, 2015) descreve que "à la carte é a técnica de serviço em que é apresentada ao cliente a carta de menu ou cardápio, no qual estão discriminados os pratos com seus respectivos preços”. Porém, existe também um contra movimento que busca, nas marmitarias, uma tentativa de retornar ao padrão alimentar, com restrições sobre o ato de cozinhar, mas depositando, 
na empresa de viandas e marmitarias, a segurança de um alimento de boa qualidade nutricional.

Hoje em dia, a procura por alimentação rápida cresceu em demasia. Um forte exemplo é o food truck, é um utilitário que pode vender comida em vários locais, tem contato direto com o público, é de baixo custo e não tem necessidade de adquirir ponto comercial ou outros encargos. Esse novo empreendimento é uma nova tendência e é atividade de fonte de renda de muitas famílias, sendo que essas atividades já representam quase $2 \%$ da população brasileira, embora seja atividade antiga, começou a inovar a partir da primeira década do século 21, com a modalidade de negócio food truck. (SEBRAE, 2016). Na próxima subseção, aborda-se a pesquisa de mercado.

\subsection{PESQUISA DE MERCADO}

A pesquisa de mercado é uma ferramenta para obter informações sobre o mercado que se atua ou pretende atuar. Quanto maior for o conhecimento sobre mercado, clientes, fornecedores, concorrentes, maior será o potencial de desempenho do empreendimento, bem como serve para abertura ou expansão de um novo negócio, para desenvolver uma análise de mercado.

Para o Sebrae (2015), a pesquisa é um recurso fundamental que serve para conhecer o perfil do cliente, sendo que a pesquisa proporciona a caracterização dos clientes nos aspectos quantitativos (potencial do mercado, participação da empresa no mercado etc.) e qualitativos (estilo de vida, características comportamentais, hábitos de consumo, escolaridade, renda etc.). Serve, também, para saber a perspectiva do mercado, identificar o segmento do mercado mais lucrativo, detectar novas tendências, avaliar o desempenho de seus produtos e serviços, identificar a quantidade ou o volume que o mercado é capaz de absorver e a que preços esses produtos poderão ser vendidos. (SEBRAE, 2015).

Para Pinheiro (2009), a pesquisa de mercado, como instrumento de assistência à administração mercadológica, pode ser uma ferramenta poderosa de análise de mercado e de interpretação da realidade, que colabora com a resposta dessas outras questões relevantes do mundo empresarial. Conforme Pinheiro et al. (2005), a pesquisa de mercado, como ferramenta, é uma boa opção para as empresas, pode ser um mecanismo eficiente de estudo de mercado e de compreensão da veracidade, que auxilia com a 
resposta dessas e outras questões consideráveis do mundo empresarial. Na sequência, aborda-se sobre a importância das informações de mercado para o empreendedor avaliar o cenário dos negócios.

\subsubsection{Informações para análise de mercado}

O principal entendimento para uma organização utilizar uma pesquisa de mercado é a descoberta de uma oportunidade de mercado. De acordo com Pinheiro et al. (2005), uma pesquisa pode ser realizada para avaliar oportunidades de mercado, outra para desenvolver opções de segmento de mercado, outra ainda para compreender as atitudes e o comportamento do consumidor.

Existe uma série de fatores que podem ser analisados para que se possa construir um esquema nítido das circunstâncias de mercado, a saber: macro e microambiente, comportamento, necessidades, desejos e características do consumidor/cliente e ambiente interno da organização. Neste sentido, descreve-se:

- Análise do macroambiente e do microambiente - diz respeito
às condições da economia, legislação, tecnologia, demografia,
ecologia, política e cultura, à estimativa do potencial do
mercado consumidor, à análise do mercado intermediário, à
evolução do mercado, a demanda por segmento, às diferenças
regionais, ao surgimento e crescimento de novos mercados, à
concorrência direta e indireta, concorrência entre
produtos/serviços.
- Análise do comportamento, necessidades, desejos e
características do consumidor/cliente - trata-se do perfil
demográfico e psicográfico do consumidor, das razões de
compra, das atitudes e opiniões, das motivações de consumo, da
identificação de hábitos e costumes, das necessidades e desejos
que estão sendo satisfeitos. - Ambiente interno - recursos e capacitações de marketing, produção, finanças e tecnologia (PINHEIRO et al., 2005, p.65).

Para o Sebrae (2015), as sentenças relacionadas a novos empreendimentos contêm certo grau de dúvida, tanto no que diz respeito à informação, na qual as decisões estão fundadas, como no que diz respeito às suas consequências. Assim, o sucesso de uma pesquisa de mercado é um instrumento de orientação para as decisões. 
A informação, por si só, não leva à decisão nem ao resultado, é preciso escolher um método de ação que ajude a identificar problemas e oportunidades e que indique caminhos que reduzam as incertezas. Não há qualquer argumento para fazer-se uma pesquisa mercadológica se o tomador de decisão não pretende alterar a sua posição inicial, não acredita ou não compreende os seus verdadeiros resultados (MALHOTRA, 2011).

A edição de fevereiro de 2014 da revista Exame mostra algumas ferramentas de pesquisa de mercado para novos empreendedores com a finalidade de garantir resultados satisfatórios, que são:

1. Survey Monkey - $\mathrm{O}$ site permite que os empreendedores criem questionários e enviem por e-mail durante a pesquisa. A versão gratuita inclui 10 perguntas por questionário e até 100 respostas. Ele gera gráfico e tabulação automaticamente. A versão paga, a partir de 299 reais ao ano, dá acesso a formulários e respostas ilimitados e permite cruzar dados.

2. Google Drive - Alternativa ao Survey Monkey, o Google também tem uma opção de formulário que pode ser customizado e enviado aos entrevistados. Neste caso, o empreendedor precisa saber interpretar e cruzar os dados. O serviço só reúne as respostas.

3. Mercado de ações - Uma maneira barata de conhecer outros mercados é analisando os dados de empresas do mesmo segmento que têm capital aberto. Sites sobre o mercado financeiro reúnem informações sobre faturamento e lucro dessas empresas que podem ser úteis na hora de elaborar um planejamento financeiro, por exemplo.

4. Sua Pesquisa - O site Sua Pesquisa é uma versão brasileira do Survey Monkey. É possível fazer questionários, espalhar a pesquisa e coletar os dados para decisões. Há uma versão gratuita que permite enviar um formulário e ter até 30 respostas e é possível cruzar os dados.

5. Redes sociais - Usar as suas redes sociais para coletar dados pode ser uma boa opção. O principal cuidado é ao escolher quem será o público. Para um negócio de cosméticos, por exemplo, um caminho seria participar de grupos sobre o tema e interagir, com autorização, fazendo perguntas pontuais.

6. BizStats - Este site reúne informações e estatística financeiras de vários setores, tudo de graça. É possível encontrar relatórios financeiros, análises de risco e lucratividade, e ferramentas úteis de finanças. A dica é buscar empresas que são referências na área do seu negócio e encontrar valores de faturamento e investimento.

7. CrunchBase - Para startups, o site TechCrunch e sua base de dados de empresas é o ponto de partida. Ali, é possível encontrar quais negócios já receberam investimentos, quais fundos de interessam pelo seu setor e outras informações sobre startups de todo o mundo. 
8. Google Trends - Para quem ainda só tem uma boa ideia ou precisa definir um setor de atuação, a ferramenta Google Trends pode ajudar. É possível saber o que as pessoas mais estão pesquisando na internet, inclusive definindo um território para a busca e comparando dois ou mais termos.

9. IpeaData - Conhecer melhor os índices sociais e econômicos da região em que se pretende atuar é uma das premissas do plano de negócios. Hoje, o instituto de Pesquisa Econômico Aplicada (IPEA) reúne diversos dados do país em seu site, como indicadores macroeconômicos, regionais e sociais.

10. PiniOn - Este aplicativo funciona como uma ferramenta de coleta de dados para empresas. É útil para negócios que já estão em operação e tem algum capital para investir. $\mathrm{O}$ empresário cria uma missão e os usuários recebem recompensas em dinheiro para dar opiniões e ideias sobre os produtos. O serviço custa a partir de dois mil reais (ZUINI, 2014).

As ferramentas de pesquisa citadas são relevantes para os empreendedores, em especial para o ramo de alimentação, e têm o potencial de constituir-se em ferramentas técnicas ou até mesmo ferramentas mais simples, como solicitar informação à família ou amigos. Tudo é válido e precioso para obter êxito em seus negócios. Na próxima subseção, aborda-se o processo de decisão e as suas características.

\subsection{PROCESSO DE DECISÃO}

O processo de decisão é cognitivo e escolhe um plano de ação dentre vários outros baseados em vários cenários, ambientes, análises e fatores para uma situação ou problema. Segundo Andrade e Amboni (2010, p. 204), “o processo da tomada de decisão em organizações envolve passos ou fases para se chegar à efetiva tomada de decisão de acordo com os objetivos da organização". Todo processo decisório causa uma escolha, ou seja, a tomada de decisão refere-se ao processo de escolher o caminho mais adequado à empresa, em uma determinada circunstância.

Para Andrade (2009), as principais características do processo de tomada de decisão, que têm enorme importância na conceituação de racionalidade da ação gerencial, são: a) o processo de tomada de decisão é sequencial; b) é um processo complexo; c) implica valores subjetivos; e d) é desenvolvido dentro de um ambiente institucional com regras mais ou menos definidas. Essas características, descritas por Andrade (2009), são explicadas no Quadro 1 a seguir. 


\begin{tabular}{|l|l|}
\hline \multicolumn{1}{|c|}{ Característica } & \multicolumn{1}{c|}{ Descrição } \\
\hline Processo sequencial & $\begin{array}{l}\text { A decisão é consequência de uma série de fatos anteriores que criaram } \\
\text { as bases para chegar-se a ela. A decisão resulta de uma coletânea de } \\
\text { muitas decisões que abrangem um leque de aspectos do problema e que, } \\
\text { frequentemente, requer muito tempo. }\end{array}$ \\
\hline Processo complexo & $\begin{array}{l}\text { Quase sempre a informação relativa ao problema é insuficiente. O } \\
\text { processo de tomada de decisão consiste em uma inter-relação entre } \\
\text { pessoas, responsabilidades pelo serviço, comunicação e sistemas de } \\
\text { informações, códigos de ética e moral e, às vezes, interesses e objetivos } \\
\text { diferentes dos participantes. }\end{array}$ \\
\hline $\begin{array}{l}\text { Processo que implica } \\
\text { valores subjetivos }\end{array}$ & $\begin{array}{l}\text { A maior parte dos processos que se deve seguir para preparar melhores } \\
\text { decisões é identificável e clara, podendo ser repetida por outras pessoas } \\
\text { ou em outras ocasiões. É enorme o número de fatores intuitivos } \\
\text { provenientes de experiência pessoal e da personalidade do gestor } \\
\text { envolvido no processo de tomada de decisão. Evidentemente, não se } \\
\text { pode negar a importância desses fatores na qualidade da decisão } \\
\text { tomada. }\end{array}$ \\
\hline $\begin{array}{l}\text { Processo em ambiente } \\
\text { institucional }\end{array}$ & $\begin{array}{l}\text { As companhias têm estruturas organizacionais próprias que influenciam } \\
\text { e, muitas vezes, regulam o processo de tomada de decisão. }\end{array}$ \\
\hline
\end{tabular}

Quadro 1 - Características do processo de tomada de decisão

Fonte: Adaptado de Andrade (2009).

Segundo Andrade e Amboni (2010), a tomada de decisão provoca uma opção apontar, em algumas alternativas, uma atividade que venha a resolver o problema ou alavancar a oportunidade. A inter-relação entre pessoas, a maneira como se processa o fluxo de informações, as características da organização e o sistema hierárquico são fatores que afetam fundamentalmente o processo de tomada de decisão.

Para Chiavenato (2000), o administrador deve constantemente saber o que fazer, como, quando, onde, quem e, muitas vezes, como deve fazer. Seja regular objetivo, destinar recursos ou resolver problemas que surgem pelo caminho, o administrador deve medir o efeito da decisão de hoje sobre as oportunidades de amanhã. Em toda decisão, existem, no mínimo, seis elementos, a saber:

1. O tomador de decisão: é o indivíduo ou grupo de indivíduos que faz uma escolha dentre vários cursos de ação disponíveis.

2. Objetivos: são os objetivos que o tomador de decisão pretende alcançar por meio de suas ações. 
3. O sistema de valores: são os critérios de preferência que o tomador de decisão usa para fazer sua escolha.

4. Cursos de ação: são as diferentes sequências de ação que o tomador de decisão pode escolher.

5. Estado da natureza: são aspectos do ambiente que envolvem o tomador de decisão e que afetam sua escolha de cursos de ação. São fatores ambientais fora do controle do tomador de decisões, como as condições de certeza, risco ou incerteza, que veremos adiante.

6. Consequências: representam os efeitos resultantes de um determinado curso de ação e de um determinado estado da natureza (CHIAVENATO, 2000, p. 172, grifo do autor).

O processo de decisão pode ser simples ou complexo, dependendo do grau de complexidade, do objetivo a ser alcançado e dos reflexos da escolha na vida pessoal ou profissional do indivíduo. Para fechar essas considerações, Maximiano (2011, p. 17) entende que: "Tomar decisões é a essência do trabalho de administrar. Tão importante é o processo de decidir para a administração que se pode entender os dois como sinônimos. Quando você administra, está tomando decisões, e vice-versa.”. Na sequência, enfoca-se a metodologia que embasou este trabalho.

\section{METODOLOGIA}

Para a realização deste trabalho foram escolhidas estratégias e técnicas peculiares para abordar o tema e o problema de forma clara, assim sendo, a primeira parte caracteriza-se como pesquisa bibliográfica e descritiva. Trata-se de uma pesquisa de cunho bibliográfico, pois foram consultados livros e artigos para a construção do referencial teórico que serviu como base para a análise dos dados coletados no decorrer do trabalho. (MARCONI E LAKATOS, 2003).

Para Marconi e Lakatos (2003), a pesquisa bibliográfica é um apanhado geral sobre os principais trabalhos realizados, revestido de importância, por serem capazes de fornecer dados atuais e relevantes relacionados com o tema. O estudo da literatura pertinente pode ajudar a planificação do trabalho, evitar publicações e certos erros e representa uma fonte indispensável de informações, podendo até orientar as indagações.

Gil (1999) explica que a pesquisa bibliográfica é desenvolvida mediante material já elaborado, principalmente livros e artigos científicos. Apesar de praticamente todos 
os outros tipos de estudo exigirem trabalho dessa natureza, há pesquisas exclusivamente desenvolvidas por meio de fontes bibliográficas.

Por outro lado, na concepção de Gil (1999), a pesquisa descritiva tem como principal objetivo escrever características de determinada população ou fenômeno ou o estabelecimento de relações entre as variáveis. Uma de suas características mais significativas está na utilização de técnicas padronizadas de coletas de dados.

Infere-se do exposto que a pesquisa descritiva configura-se como um estudo intermediário entre a pesquisa exploratória e a explicativa, ou seja, não é tão preliminar como a primeira nem tão profunda como a segunda. Vergara (1988) descreve que a pesquisa descritiva apresenta características de determinada população ou determinado acontecimento. Ela pode, da mesma forma, determinar correlações entre variáveis e aclarar a sua natureza, não tem compromisso de desvendar os fenômenos que descreve, se bem que sirva de base para tal explicação. Nesse contexto, descrever significa identificar, relatar, comparar, entre outros aspectos. Além disso, o seu formato é o de um estudo de caso, pois o foco de pesquisa é as microempresas do ramo de viandas e marmitarias.

Quanto à abordagem escolhida, ela é qualitativa, para responder aos objetivos do estudo. A abordagem qualitativa determina uma ligação entre o mundo real e o indivíduo. Marconi e Lakatos (2011, p. 269) afirmam que: "O método qualitativo difere do quantitativo não só por não empregar instrumentos estatísticos, mas também pela forma de coleta e análise de dados".

Para Andrade (2010), na coleta de dados, deve-se realizar um projeto que singularize os pontos de pesquisa e os parâmetros para a apuração dos possíveis envolvidos e dos participantes que responderão aos questionários. $\mathrm{O}$ roteiro semiestruturado foi elaborado contendo cinco questões que tratam de abordar o perfil do entrevistado, sete perguntas abertas para proporcionar uma maior compreensão do fenômeno e onze perguntas fechadas com duas alternativas: "SIM e NÃO".

De acordo com Marconi e Lakatos (2003), a entrevista é "um encontro entre duas pessoas, a fim de que uma delas obtenha informação a respeito de determinado assunto, mediante uma conversação de natureza profissional”. No presente estudo, o universo da pesquisa constituir-se-á de MEs do ramo de viandas e marmitarias de Santa Maria, RS. 
Santa Maria é um munícipio do estado do Rio Grande do Sul, no Brasil, que possui população total de 375.317 habitantes, segundo dados do FEEDADOS em 2015, sendo considerada uma cidade média e de grande importância na região central do estado. É a quinta cidade mais populosa do Rio Grande do Sul. Santa Maria é considerada uma cidade universitária, por ter uma grande quantidade de instituições de ensino superior. Por isso, a cidade possui um fluxo enorme de estudantes, o que imprime uma enorme demanda na parte da alimentação.

O presente estudo foi realizado na área central da cidade de Santa Maria, RS. As bases econômicas do município são os comerciantes, os servidores públicos, incluindo os da Universidade Federal de Santa Maria (UFSM) e os militares. O método utilizado no levantamento de dados foi uma entrevista semiestruturada, que foi aplicada em dez microempresas, no segmento de fornecimento de refeições em viandas e marmitarias. A escolha delas foi embasada na facilidade de acesso e no tempo de deslocamento do pesquisador.

As dez empresas pesquisadas oferecem serviços de tele-entrega em qualquer região da cidade e disponibilizam máquinas de cartões de crédito para os entregadores e cardápios variados de segunda a sábado. A entrevista com o roteiro semiestruturado foi aplicada aos empreendedores de forma presencial, sendo a coleta realizada no horário de grande fluxo de clientes, compreendido pelo horário corriqueiro de consumo do almoço, entre 11 e 15h, e aplicada nos meses de setembro e outubro de 2016.

O roteiro semiestruturado foi criado pelo autor e dividido em três seções. A primeira seção foi elaborada com cinco perguntas para identificar o perfil dos entrevistados, a segunda contém sete perguntas abertas e a terceira seção foi elaborada com onze perguntas sobre a satisfação e o uso do instrumento.

Os fatores de escolha da cidade e dos empreendedores foram definidos considerando que a cidade possui grande número de estudantes e trabalhadores que circulam nessa região e optam por esse meio de alimentação, por ser viável e rápido.

Os dados coletados foram analisados, interpretados e representados por quadros e tabelas. Na próxima seção, será realizada a discussão de resultados da pesquisa com base na análise e na interpretação das entrevistas. 


\section{APRESENTAÇÃO E DISCUSSÃO DOS RESULTADOS}

Nesta seção, apresentam-se os resultados desta pesquisa, através de entrevistas com representantes de dez (10) empresas do setor de viandas e marmitarias na região central de Santa Maria/RS.

Inicialmente, apresentam-se os dados coletados para identificar o perfil dos sujeitos participantes da pesquisa. Foram entrevistadas dez (10) pessoas, sendo nove (09) homens e uma (01) mulher; entre eles, seis (06) proprietários, dois (02) sócios proprietários, um (01) gerente e um (01) supervisor. Em relação à escolaridade, cinco (05) possuem ensino médio completo, um (01) possui ensino técnico em administração, dois (02) possuem ensino superior completo, sendo que um deles cursou especialização em gestão de pessoas e dois (02) estão cursando administração.

Nota-se que, em relação ao grau de escolaridade, metade dos entrevistados, ou seja, cinco (05) deles, só possui ensino médio, conforme relato dos empresários, a razão maior para isso é a falta de tempo, pois, nesse ramo, ocupa-se tempo integral para dedicar-se ao negócio e torna-se impossível o aperfeiçoamento na área ou afins. Já os outros cinco (05) buscaram cursos técnicos e graduação porque acreditam que somente o estudo leva ao sucesso no empreendedorismo e pretendem adequar-se mais ainda nessa área que cresce a cada ano.

Com relação à faixa etária, dois (02) têm idade entre 21 e 26 anos, dois (02) têm idade entre 27 e 32 anos, um (01) tem idade entre 33 e 38 anos, um (01) tem idade entre 39 e 44 anos e quatro (04) têm acima de 44 anos. Em relação aos anos de existência das empresas no mercado, dois (02) possuem menos de um (01) ano, dois (02) possuem de um (01) a três (03) anos, dois (02) possuem de três (03) a cinco (05) anos e quatro (04) possuem mais de dez (10) anos. Percebe-se que os entrevistados representam idades diferentes, isso mostra que a idade não simboliza a quantidade de anos que a empresa está atuando no mercado, pois nem sempre o empresário que possui maior idade é o que atua há mais tempo no mercado.

$\mathrm{Na}$ sequência, os respondentes foram questionados especificamente sobre a pesquisa de mercado, por meio de sete perguntas abertas, que terão as suas respostas apresentadas e analisadas a seguir. A primeira pergunta referia-se ao processo de 
criação da empresa no setor de viandas e marmitarias. O Quadro 2 sintetiza as respostas obtidas.

\begin{tabular}{|c|l|}
\hline Respondente & \multicolumn{1}{|c|}{ Relato sobre a criação da empresa } \\
\hline A & $\begin{array}{l}\text { Experiência anterior no ramo de alimentação como chefe de cozinha em um } \\
\text { restaurante. Com essa experiência, percebeu que tinha condições para abrir o } \\
\text { seu próprio negócio. Acreditou que daria certo abrir o seu empreendimento na } \\
\text { área central da cidade, pois há muitos estudantes e trabalhadores que não } \\
\text { possuem tempo suficiente para cozinhar. }\end{array}$ \\
\hline B & $\begin{array}{l}\text { Experiência anterior no ramo de alimentação como auxiliar de cozinha e } \\
\text { sempre teve interesse na área de alimentação. }\end{array}$ \\
\hline C & $\begin{array}{l}\text { Por ser mais cômodo para o cliente pedir o seu almoço e pelo fato de não } \\
\text { sobrar tempo de cozinhar, em razão de seus clientes trabalharem e estudarem. } \\
\text { Foi a oportunidade ímpar para a criação da empresa. }\end{array}$ \\
\hline D & $\begin{array}{l}\text { Trabalhou no Exército Brasileiro, como cozinheiro, por cinco anos e fez um } \\
\text { curso técnico em Administração. A partir de então, resolveu abrir a empresa } \\
\text { em sociedade com um amigo. }\end{array}$ \\
\hline I & $\begin{array}{l}\text { Experiência anterior em um restaurante como chefe de cozinha. A partir daí, } \\
\text { resolveu abrir a sua empresa. }\end{array}$ \\
\hline J & $\begin{array}{l}\text { Experiência no ramo de alimentação voltado para lanches e vontade de ter o } \\
\text { seu próprio negócio, pois não queria ser mais empregado. }\end{array}$ \\
\hline G & $\begin{array}{l}\text { A falta de emprego, mudança de Porto Alegre para Santa Maria e o dom em } \\
\text { cozinhar foram a oportunidade para começar um empreendimento no ramo de } \\
\text { alimentação. }\end{array}$ \\
\hline $\begin{array}{l}\text { Momento de crise, por motivo da perda da lavoura de arroz e falta de emprego } \\
\text { levaram à criação da empresa. }\end{array}$ \\
\hline Aposentadoria foi o motivo para abrir a empresa. \\
\hline Empresa familiar, já estava no mercado há anos. Só seguiu o empreendimento. \\
\hline Q
\end{tabular}

Quadro 2 - Processo de criação das empresas estudadas

Fonte: Elaborado pelo autor (2016).

No quadro, os resultados apontam que, para cada empresa participante desta pesquisa, houve um motivo diferente, uma trajetória distinta para a criação delas. Notase que cinco (05) desses empresários já tinham experiência na área de alimentação, isso comprova que ter bagagem no ramo é um dos fatores vitais para abrir um empreendimento. Apenas um abriu a empresa por possuir o dom de cozinhar e também 
pelo fato de estar desempregado, assim aproveitou a oportunidade para começar o seu negócio.

Maximiano (2011) expressa que, para vários empreendedores, o estímulo de começar uma empresa é fonte de felicidade. A chance de evoluir uma ideia em um negócio gratificante gera um enorme envolvimento de realização. Nessa alusão, em contraponto com a presente pesquisa, isso pode ser reforçado quando considerada a escolaridade dos respondentes, assim como as experiências profissionais anteriores.

Quanto à possível busca de informação para embasar o início do empreendimento no ramo de viandas e marmitarias, entre as fontes apontadas, estão Sebrae, IBGE, pessoas próximas com experiências, experiências anteriores, busca de informações com amigos e familiares, além de pesquisas na internet. Além disso, alguns respondentes afirmaram não terem buscado nenhum tipo de informação específica antes da abertura do negócio.

Para esses empresários que não buscaram nenhum tipo de informação para auxiliar no início de seus negócios, a pesquisa tem um papel fundamental para a busca de informações, porque facilita o processo de tomada de decisão. Portanto, é primordial que os empresários disponham de informações para o embasamento de seus empreendimentos. Diante disso, Messias (2005, p.19) descreve que "a informação atua enquanto um regulador da vida social, permeando todos os espaços e atuando em todas as atividades humanas".

A compreensão sobre a ferramenta pesquisa de mercado e a sua utilidade, na concepção dos entrevistados, relaciona-se a analisar o segmento em que o empreendedor quer investir, verificar a existência de público suficiente para iniciar o empreendimento, em qual região atuar, quais as necessidades dos clientes, buscar novos clientes, determinar a venda de um produto, minimizar custos e maximizar lucros.

Quanto à possível aplicação da ferramenta pesquisa de mercado no andamento de seus empreendimentos, $90 \%$ realizam, principalmente, na compra de insumos, a fim de buscar melhor preço e qualidade para a realização dos cardápios da semana. Também pesquisam se há qualidade nas refeições oferecidas pelos concorrentes, por meio da compra de marmitex fornecidas por outras empresas para analisar o sabor e, assim, melhorar a sua qualidade. 
A maioria dos entrevistados, $90 \%$ deles, sustenta que usou a ferramenta para auxiliar no andamento dos negócios no ramo de alimentação. Essa ferramenta abre inúmeras oportunidades para as empresas crescerem no ramo de viandas e marmitarias. Ademais, diminui gastos na compra de insumos, seleciona melhores fornecedores para maximizar lucros, ratifica as ideias e favorece a qualidade da comida servida para os clientes, que é o alicerce principal do negócio. Neste sentido, há analogias com o estudo de Maximiano (2011, p. 10), o qual descreve que "atender a todas as partes interessadas depende da capacidade da satisfação do cliente. Sem clientes, não há receita. Sem receita, não há lucros". Assim sendo, trata-se de um trabalho conduzido para atender as necessidades dos clientes. Cardoso (2011, apud RAYMUNDO, 2015) assinala que a maior parte das empresas do setor de alimentos e bebidas é empreendimentos de pequeno porte e que, muitas vezes, não emprega ferramentas ideais para conduzir os seus negócios.

Quanto à preparação dos empreendedores para efetuar algum tipo de pesquisa de mercado sem o auxílio de alguém ou consultoria, os resultados obtidos são apresentados no Quadro 3, a seguir.

Respondente

Relato dos entrevistados

\begin{tabular}{|c|l|}
\hline Respondente & \multicolumn{1}{|c|}{ Relato sobre a criação da empresa } \\
\hline A & $\begin{array}{l}\text { Experiência anterior no ramo de alimentação como chefe de cozinha em um restaurante. } \\
\text { Com essa experiência, percebeu que tinha condições para abrir o seu próprio negócio. } \\
\text { Acreditou que daria certo abrir o seu empreendimento na área central da cidade, pois há } \\
\text { muitos estudantes e trabalhadores que não possuem tempo suficiente para cozinhar. }\end{array}$ \\
\hline B & $\begin{array}{l}\text { Experiência anterior no ramo de alimentação como auxiliar de cozinha e sempre teve } \\
\text { interesse na área de alimentação. }\end{array}$ \\
\hline C & $\begin{array}{l}\text { Por ser mais cômodo para o cliente pedir o seu almoço e pelo fato de não sobrar tempo de } \\
\text { cozinhar, em razão de seus clientes trabalharem e estudarem. Foi a oportunidade ímpar } \\
\text { para a criação da empresa. }\end{array}$ \\
\hline D & $\begin{array}{l}\text { Trabalhou no Exército Brasileiro, como cozinheiro, por cinco anos e fez um curso técnico } \\
\text { em Administração. A partir de então, resolveu abrir a empresa em sociedade com um } \\
\text { amigo. }\end{array}$ \\
\hline E & $\begin{array}{l}\text { Experiência anterior em um restaurante como chefe de cozinha. A partir daí, resolveu } \\
\text { abrir a sua empresa. }\end{array}$ \\
\hline
\end{tabular}




\begin{tabular}{|c|l|}
\hline F & $\begin{array}{l}\text { Experiência no ramo de alimentação voltado para lanches e vontade de ter o seu próprio } \\
\text { negócio, pois não queria ser mais empregado. }\end{array}$ \\
\hline G & $\begin{array}{l}\text { A falta de emprego, mudança de Porto Alegre para Santa Maria e o dom em cozinhar } \\
\text { foram a oportunidade para começar um empreendimento no ramo de alimentação. }\end{array}$ \\
\hline H & $\begin{array}{l}\text { Momento de crise, por motivo da perda da lavoura de arroz e falta de emprego levaram à } \\
\text { criação da empresa. }\end{array}$ \\
\hline I & Aposentadoria foi o motivo para abrir a empresa. \\
\hline J & Empresa familiar, já estava no mercado há anos. Só seguiu o empreendimento. \\
\hline
\end{tabular}

Quadro 3 - Preparação dos empreendedores quanto à utilização da ferramenta pesquisa de mercado

Fonte: Elaborado pelo autor (2016).

No quadro 3, os resultados demostraram que boa parte dos empresários, ou melhor, $80 \%$ estão preparados para efetuar algum tipo de pesquisa de mercado, mas, dependendo do grau da pesquisa, eles relataram que podem recorrer a alguém mais qualificado, pois pesquisas mais simples, como selecionar fornecedores mais viáveis e a compra de insumos, seriam feitas por conta e risco. Os outros dois (02) que não se sentem preparados para efetuar a pesquisa de mercado declaram que desconhecem essa ferramenta e não estão preparados para empregar em suas empresas. $\mathrm{O}$ fato de eles desconhecerem a ferramenta associa-se ao grau de escolaridade dos empresários, uma vez que não possuem curso superior ou até mesmo cursos profissionalizantes na área mercadológica.

Tal constatação demonstra a relevância da ferramenta de pesquisa de mercado em suas empresas, além disso, a possibilidade de seus empreendimentos crescerem é ainda maior, em especial, nesse nicho de viandas e marmitarias que está cada vez mais abundante em Santa Maria. Bleil (1998, p. 15) descreve que "No passado o indivíduo comia para viver. Hoje em dia, o consumismo induz a sociedade a viver para comer". Desse modo, os pesquisadores constatam a importância, porém, ainda não realizam pesquisas de mercado, o que pode dificultar a compreensão sistêmica e a detecção de oportunidades de mercado.

Além disso, foi solicitada aos 10 respondentes uma série de questões com respostas fechadas (SIM/NÃO) para a detecção do uso da ferramenta de pesquisa de mercado. Os resultados obtidos são apresentados na Tabela 1, a seguir. 


\begin{tabular}{l|c|c}
\hline \multicolumn{1}{c|}{ Perguntas } & SIM & NÃO \\
\hline Solicitou consultoria antes de abrir o seu empreendimento? & $50 \%$ & $50 \%$ \\
\hline $\begin{array}{l}\text { Realizou algum tipo de pesquisa de mercado para saber os hábitos de } \\
\text { consumo, fatores que motivam a compra e características de seus clientes? }\end{array}$ & $50 \%$ & $50 \%$ \\
\hline $\begin{array}{l}\text { Realizou algum tipo de pesquisa de mercado para identificar os seus } \\
\text { principais concorrentes para a sua empresa ganhar vantagens estratégicas? }\end{array}$ & $60 \%$ & $40 \%$ \\
\hline $\begin{array}{l}\text { Realizou alguma pesquisa para explorar fornecedores mais viáveis em } \\
\text { relação custo/benefício para o seu negócio? }\end{array}$ & $80 \%$ & $20 \%$ \\
\hline $\begin{array}{l}\text { Fez um estudo para concessão de crédito para os seus clientes antes de } \\
\text { vender a prazo? }\end{array}$ & $0 \%$ & $10 \%$ \\
\hline $\begin{array}{l}\text { Realizou pesquisa de mercado sobre ambiente demográfico para identificar } \\
\text { população humana em termos de tamanho, densidade, localização, idade, } \\
\text { sexo, raça, ocupação e outros dados estatísticos? }\end{array}$ & $10 \%$ & $90 \%$ \\
\hline $\begin{array}{l}\text { Realizou pesquisa de mercado sobre questões econômicas para analisar } \\
\text { crescimento de renda, empregos e crédito que podem afetar a empresa? }\end{array}$ & $20 \%$ & $80 \%$ \\
\hline $\begin{array}{l}\text { Investe em tecnologia no seu empreendimento? } \\
\text { Acredita que a pesquisa de mercado surte efeitos positivos para o seu } \\
\text { negócio? }\end{array}$ & $10 \%$ & $0 \%$ \\
\hline
\end{tabular}

Tabela 1 - Utilização da ferramenta pesquisa de mercado

Fonte: Elaborado pelo autor (2016).

Houve um equilíbrio entre os respondentes sobre a solicitação de algum tipo de consultoria antes de abrir os seus negócios, pois metade dos respondentes, 50\%, assimilou que é importante recorrer à consultoria. Isso reflete que 50\% desconhecem a ferramenta para começar os seus negócios. O fato dos empresários não buscarem ajuda tem relação com o modo de eles pensarem, pois, em sua opinião, é preciso apenas força de vontade e um bom capital inicial para ser um empreendedor de sucesso e não fazer uma pesquisa correta para conhecer o mercado.

Na pergunta seguinte, também houve um equilíbrio nas respostas sobre hábitos de consumo dos clientes. Esse equilíbrio, que ocorreu nas duas primeiras questões, tem relação com o grau de escolaridade dos entrevistados, uma vez que a metade deles não possui ensino superior ou algum curso técnico na área. Isso reflete no desconhecimento da metade deles quanto à ferramenta pesquisa de mercado.

$\mathrm{Na}$ pergunta subsequente, $60 \%$ dos entrevistados responderam que fizeram a pesquisa sobre a identificação de seus principais concorrentes e 40\%, não. Esses 
números demonstram que os empresários planejaram-se quanto à concorrência, sendo um fator relevante para o negócio progredir diante de seus opositores. Por outro lado, os outros responderam que não se importam com a concorrência, pois assinalaram que só depende deles para fazer um bom trabalho diante de seus clientes e que acreditam na qualidade de seus produtos.

A pesquisa revelou que $80 \%$ dos entrevistados responderam que realizam pesquisas para explorar fornecedores. Os empresários de viandas afirmam que a pesquisa é constante, porque as qualidades dos produtos variam muito e os preços mudam com muita frequência, ainda mais no ramo de alimentação que deve priorizar a qualidade das refeições e evitar subida de preços para seus clientes, por isso a maioria recorre a esse tipo de pesquisa. Para Kotler e Keller (2006), “o comprador tenta identificar os fornecedores mais apropriados. Ele examina listas e catálogos comerciais, telefona para outras empresas em busca de recomendações, assiste a comerciais e frequenta feiras setoriais".

Todos os dez empreendedores responderam que não fizeram estudo para a concessão de crédito para os clientes, visto que, hoje em dia, vende-se no cartão de crédito, auxílio-alimentação das empresas que concedem esse benefício aos trabalhadores e também pelo motivo de não ser viável a venda com boletos, cheques ou até mesmo na antiga caderneta, pois o índice de inadimplência, nesses casos, é muito alto. Os métodos dos clientes efetuarem o pagamento são nas opções diária, semanal e mensal. Pode ser efetuado direto na empresa ou até mesmo a pedido do cliente, o próprio serviço de telemoto pode receber levando a máquina de cartão de crédito direto ao consumidor. Tal fato, segundo os empresários, favorece em comodidade e agilidade para ambas as partes.

Apenas um respondente afirmou que fez a investigação sobre a realização da pesquisa de mercado sobre ambiente demográfico, população humana, densidade, localização, idade e outros dados. Dentre as razões dos empresários não fazerem essa pesquisa, tem-se que eles são naturais de Santa Maria e acham que conhecem os gostos e costumes da população. Outra razão é que essa pesquisa é muito complexa e trabalhosa, por isso, só um empresário fez o estudo. Outra resposta relevante foi o fato de todas as empresas pesquisadas investirem em tecnologia, pois é, de extrema importância para eles, tal investimento. Na concepção de Megliorine (2007, p. 312 apud RAYMUNDO, 2015), “o empreendedor pode deter a tecnologia necessária para fazer 
produtos ou prestar serviços com qualidade, mas há casos em que o volume de vendas não é suficiente para gerar o lucro necessário".

Os $90 \%$ dos respondentes acreditam que a pesquisa de mercado surte efeitos positivos, porque o comprovam principalmente na lucratividade de seus negócios e na satisfação de seus clientes no consumo de suas viandas. Os empresários acreditam na ferramenta, mas não colocam em prática em seus negócios. Os empreendedores sabem da importância de estudar e aprofundar-se na área, porém não o fazem. Isso comprova que os empresários abrem os seus negócios às escuras e não pensam no futuro de suas empresas, a respeito de desenvolvimento e longevidade delas no mercado.

Quatro (04) respondentes, totalizando 40\%, analisam-se como satisfeitos e 60\% analisam-se como muito satisfeitos na análise da ferramenta pesquisa de mercado no processo de suas empresas. Tal posicionamento reflete consideravelmente na questão dos negócios andarem de acordo com as suas perspectivas, mesmo com a crise que se passa em nosso país, como o parcelamento dos salários dos Servidores Públicos Estaduais e a demasiada concorrência de fornecimento de viandas e marmitarias na região centro de Santa Maria/RS.

Sobre com que frequência os empreendedores realizam a pesquisa de mercado, $10 \%$ responderam que não realizam, $20 \%$ realizam trimestral e $70 \%$ realizam mensalmente de um total de $100 \%$. A maioria realiza mensalmente porque busca pesquisar fornecedores constantemente, a fim de melhorar a qualidade e maximizar os lucros sem elevar os preços para os clientes que buscam refeições de qualidade, sem abrir mão de economizar, pois a maioria dos clientes é formada por estudantes e trabalhadores. Os empresários não realizam pesquisa de mercado nos moldes do estudo. Eles realizam uma consulta, uma busca de informações que serve para gerenciar os seus empreendimentos.

Os respondentes iniciaram os seus empreendimentos sobre várias formas de oportunidades de negócio, a maioria deles, ou seja, 50\% foram pelo mesmo motivo de experiências anteriores para empreender. Esse dado mostra que, para começar um negócio, deve haver o mínimo de conhecimento, principalmente, no ramo de alimentação.

Os empresários fizeram pesquisas simples para os seus empreendimentos como buscaram informações na internet, amigos e parentes. Assim mesmo não é suficiente 
para as empresas ganharem espaços no mercado, pois cresce em demasia e a concorrência expande no cenário do ramo de alimentação. A pesquisa de mercado é muito mais ampla e complexa para dar início e continuidade aos empreendimentos. Polignano (2011 apud Ribeiro et al., 2010, p. 152) considera que "pesquisa de mercado pode auxiliar no desenvolvimento de produtos como um mecanismo de captação das necessidades dos consumidores, monitorando os seus hábitos e as suas atitudes, além de avaliar os protótipos dos produtos". Neste sentido, a pesquisa de mercado é uma condição sine qua non para o sucesso das empresas de alimentação. A seguir, são tecidas as considerações finais deste estudo.

\section{CONSIDERAÇÕES FINAIS}

A pesquisa alcançou o objetivo de analisar a utilização da ferramenta de pesquisa de mercado pelos empresários do ramo de fornecimento de viandas e marmitarias no município de Santa Maria, Rio Grande do Sul. Pode-se reconhecer que o instrumento utilizado na coleta de dados, em forma de roteiro semiestruturado, obteve os objetivos propostos e demonstrados inicialmente. Com base neste estudo, pode-se comprovar que as microempresas estudadas utilizam a ferramenta de pesquisa de mercado por conta própria e de maneira mais simples possível, uma vez que, conforme as entrevistas, os empresários não fazem uma pesquisa de mercado qualificada para a tomada de decisão em seus negócios.

As microempresas do ramo de viandas e marmitarias têm impacto crucial no ramo da alimentação, porque a demanda, nos dias atuais, é superabundante em razão do custo/benefício que a alimentação fora do lar traz para as famílias. Portanto, os empresários só recorrem à ferramenta de pesquisa de mercado para selecionar melhores fornecedores e, para iniciar os empreendimentos, eles buscam informações simples como pesquisas na internet, informações com parentes e amigos que tenham algum tipo de experiências na área. A pesquisa tem um elo fundamental para a busca de informações, porque facilita o processo de tomada de decisão. Assim sendo, é primordial que os empresários disponham de informações para o embasamento de seus empreendimentos e também para perdurarem no mercado.

Os resultados evidenciaram, de acordo com as entrevistas, que as empresas tiveram um processo de criação bastante semelhante como experiências anteriores no 
ramo alimentício, vontade de ter o próprio negócio e o mais importante foi a confiança de acreditar que os seus empreendimentos na área central da cidade dariam certo, pois há muitos estudantes e trabalhadores que não possuem tempo suficiente para cozinhar.

Conforme os dados pesquisados, comprovou-se que os empresários obtiveram auxílio facilitado para a criação e a manutenção de seus empreendimentos, visto que Sebrae, IBGE, FEE DADOS e outros meios de informações auxiliam os microempreendedores tanto na criação quanto no andamento das empresas no ramo de viandas e marmitarias.

A pesquisa comprovou também que os empresários conhecem ou já ouviram falar e sabem a real importância que a ferramenta de pesquisa de mercado traz em benefício dos negócios, mas não a utilizam adequadamente, pois realizam apenas pesquisas de menor expressão e que não são suficientes para minimizar os riscos que o mercado alimentício apresenta.

A análise foi feita considerando apenas dez empresas na região centro de Santa Maria, de muitas que existem na cidade. Assim, esta pesquisa não poderá ser compreendida para toda a população empresarial, ficando restrita aos respondentes da pesquisa. Todavia, vale destacar a importância deste estudo em virtude de poucas publicações de pesquisa a respeito desse tema e pela fundamental importância que as informações de pesquisa de mercado no ramo alimentício têm no sentido de servirem como referência para a elaboração do planejamento das microempresas em Santa Maria.

Portanto, é necessária uma atenção maior dos empresários quanto à ferramenta de pesquisa de mercado, pois, usando-a de maneira técnica, ela pode tornar-se um instrumento importante para a procura de informações pertinentes ao empreendimento e à obtenção de dados úteis para a formação de uma empresa, assim como para a revalidação ou o redirecionamento das estratégias do negócio.

Diante dessas considerações e dada à relevância do tema, sugere-se que sejam realizadas novas pesquisas relativas ao assunto, abrangendo maior número de entrevistados, englobando outros bairros da cidade de Santa Maria. Assim, será possível continuar contribuindo com as empresas do segmento de viandas e marmitarias que terão parâmetro para o planejamento e mais segurança para a permanência de empresas desse segmento no mercado, dessa maneira, gerando resultados positivos no ramo alimentício. 
Por fim, este estudo poderá servir como parâmetro para as microempresas do setor de viandas e marmitarias de Santa Maria utilizarem corretamente a ferramenta de pesquisa de mercado, visto que ela é de fundamental importância para facilitar e indicar a maneira de obter-se os melhores resultados e também serve como base para começar a empreender, além da continuidade de qualquer negócio.

\section{REFERÊNCIAS}

ANDRADE, L. E. Introdução à pesquisa operacional. Rio de Janeiro: LTC, 2009.

ANDRADE, M. M. Introdução à metodologia do trabalho científico. 10. ed. São Paulo: Ed. Atlas, 2010.

ANDRADE, R. O. B; AMBONI, N. Estratégias de gestão: processos e funções do administrador. Rio de Janeiro: Elsevier, 2010.

BARBOSA, L. Tendências da alimentação contemporânea. In: Pinto, M. de L;

PACHECO, J. K. Juventude, consumo \& educação 2. Porto Alegre: ESPM, 2009.

BLEIL, S. I. O padrão alimentar ocidental: considerações sobre a mudança de hábitos no Brasil. Artigo publicado no Vol. VI da Revista Cadernos de Debate, uma publicação do Núcleo de Estudos e Pesquisas em Alimentação da UNICAMP, p. 1-25, 1998.

CHIAVENATO, I. Administração: teoria, processo e prática. São Paulo: Makron Books Brasil, 2000.

EMPRESOMETRO MPE. Estatísticas: Santa Maria. 2016. Disponível em: http://empresometro.cnc.org.br/Estatisticas. Acesso em: 01 set. 2016.

FEE. Fundação de economia e estatística. FEE DADOS - Demografia - estimativas populacionais. Santa Maria. 2015. Disponível em:< http://feedados.fee.tche.br/feedados/>. Acesso em: 18 out. 2016.

FERREIRA, K. A; ALCANTARA, R. L. C. Abordagens para aplicação da estratégia de postponement: estudo multicaso em empresas da indústria de alimentos. Gest. Prod. São Carlos, v. 20, n. 2, p. 357-372, jun. 2013.

FILION, L. Empreendedorismo: empreendedores e proprietários-gerentes de pequenos negócios. Revista de Administração, São Paulo, v. 34, n. 2, p. 05-28, abri/jun. 1999. FISCHLER, C. McDonaldização dos costumes. 6. ed. Estação Liberdade, 1998. GIL, A. C. Métodos e técnicas de pesquisa social. 5. ed. São Paulo: Atlas, 1999. 
HOFFMANN, R. A; HOFFMANN, V. E; CANCELLIER, E. L. P. L. As estratégias da microempresa varejista e seus estágios de informatização. RAM, Rev. Adm. Mackenzie (Online), São Paulo, v. 10, n. 2, p. 110-134, abr. 2009.

KOTLER, P; KELLER, K. Administração de marketing. 12. ed. São Paulo: Pearson Prentice Hall, 2006.

MARCONI, M; LAKATOS, E. Fundamentos de metodologia científica. 5. ed. São Paulo: Atlas, 2003.

MARCONI, M. de A. et al. Fundamentos de metodologia científica. 7. ed. São Paulo: Atlas, 2011.

MACULAN, A. D. Estratégias de inovação e tecnologia das pequenas e médias empresas. UFRJ, ANAPD, 1995.

MAXIMIANO, A. C. A. Administração para empreendedores. 2. ed. São Paulo: Pearson, 2011.

MALHOTRA, N. K. Pesquisa de marketing: uma orientação aplicada. 6. ed. Porto Alegre: Bookman, 2011.

MESSIAS, S. C. L. Informação: um estudo exploratório do conceito em periódicos científicos brasileiros da área de Ciência da Informação. 2005. 177-194f. Dissertação (Mestrado) - Faculdade de Filosofia e Ciências - Universidade Estadual Paulista, Marília, 2005.

PINHEIRO, R. M; CASTRO, G. C; SILVA, H. H; NUNES, J. M. G. Comportamento do consumidor e pesquisa de mercado. Rio de Janeiro. 2. ${ }^{\text {a }}$ ed. Rio de Janeiro: Editora FGV, 2005.

PELISSARI, A. S. Processo de formulação de estratégias em pequenas empresas com base na cultura corporativa e competências gerenciais. 2007. $221 \mathrm{f}$. Tese (Doutorado em Engenharia de Produção) - UNIMEP, Programa de Pós-Graduação em Engenharia de Produção da Faculdade de Engenharia, Arquitetura e Urbanismo, Santa Bárbara d'Oeste, 2007.

PINHEIRO, R. M. Inteligência competitiva e pesquisa de mercado. Curitiba: IESDE Brasil, 2009.

RAMOS, H. C; CARVALHO, F; CUNHA, M. B da. Avaliação do uso do Serviço Brasileiro de Respostas Técnicas: um serviço de informação destinada à microempresa brasileira. Ci. Inf., Brasília, v. 35, n. 3, p. 255-269, dez. 2006.

RAYMUNDO, P. J. Resultados financeiros: uma análise em empresas do segmento de alimentação fora do domicílio. Gest. Prod., São Carlos, v. 22, n. 2, p. 311-325, jun. 2015. 
RIBEIRO, M. M et al. Estudo de mercado de iogurte da cidade de Belo Horizonte/MG. Rev. Ceres, Viçosa, v. 57, n. 2, p. 151-156, abr. 2010.

SEBRAE - Serviço Brasileiro de Apoio às Micro e Pequenas Empresas. Lei geral das micro e pequenas empresas. Disponível em:

http://www.sebrae.com.br/sites/PortalSebrae/artigos/entenda-as-diferencas-entremicroempresa-pequena-empresa-e-mei. Acesso em: 08 ago. 2016.

SEBRAE - Serviço Brasileiro de Apoio às Micro e Pequenas Empresas. Como montar uma fornecedora de refeições em marmita. Disponível em:

https://www.sebrae.com.br/sites/PortalSebrae/ideias/como-montar-uma-fornecedora-derefeicoes-em-marmita. Acesso em: 08 nov. 2016.

SEBRAE - Serviço Brasileiro de Apoio às Micro e Pequenas Empresas. Como montar um food truck. Disponível em:

http://www.sebrae.com.br/sites/PortalSebrae/artigos/food-truck-uma-nova-tendencia>. Acesso em: 10 nov. 2016.

VERGARA, S. C. Projetos e relatórios de pesquisa em administração. 5 ed. São Paulo: Atlas, 1998.

ZUINI, P. 10 ferramentas de pesquisa de mercado para empreendedores. Exame, 2014. Disponível em: http://exame.abril.com.br/pme/noticias/10-ferramentas-de-pesquisa-demercado-para-empreendedores. Acesso em: 10 ago. 2016. 